\title{
Rhetorical Moves Analysis in Soft and Hard Science Lecturers' Master's Thesis and Dissertation Abstracts
}

\author{
Fadlila Ghifarina Gani ${ }^{1}$ Eri Kurniawan ${ }^{1, *}$ Wawan Gunawan ${ }^{1}$ Arif Husein Lubis ${ }^{2}$
}

\author{
${ }^{1}$ English Education Department, Universitas Pendidikan Indonesia \\ ${ }^{2}$ Korean Education Department, Universitas Pendidikan Indonesia \\ *Corresponding author. Email: eri_kurniawan@upi.edu
}

\begin{abstract}
Move analysis is usually used to analyse academic writing and to investigate the rhetorical pattern of the text. However, the analysis of rhetorical moves in the abstract of lecturers' final paper in different disciplines may not have been done. This study aims to analyse and compare the rhetorical moves (pattern), steps, and the language features used in the abstracts of the final papers. The researcher focused on the abstract of master theses and dissertations from different disciplines. This study analysed 4 abstracts from English lecturer for the soft science field and Mathematic lecturer for the hard science field in Universitas Pendidikan Indonesia. The Five Move Analysis by Hyland (2000) is used as the framework of this study. The study indicated that both of the lecturers in different disciplines commonly wrote all the moves which are Introduction - Purpose - Method - Product - Conclusion in their abstracts. However, the percentage of the used moves for each abstract are different. Besides that, there is a cycle of moves in the abstract for the hard science field. There is no significant contrast between two disciplines on steps usage. For the linguistic features, both of the abstract use similar features. In conclusion, both disciplines have their signatures and similarities in writing an abstract.
\end{abstract}

Keywords: Abstract, language features, move analysis, rhetorical move

\section{INTRODUCTION}

Writing in academic context is a challenging field and a must especially for the lecturers. Writing and publishing are fundamental to the development of a successful academic career (Antoniou \& Moriarty, 2008). The example of writing in academic context is writing a research article.

In accordance with the writing research article, research article abstracts have become an important part-genre (Swales \& Feak, 2009). It is hard and impossible for the scholars to read many research articles one by one when doing research. Since there are many research published, the scholars must be selective in their reading. So, the abstract section is needed because it is a part of research articles that describes the whole research also as the main gate for the readers to know the focus of the research. An abstract is the representation of a larger work in the form of selfcontained, short and powerful statement (Muhartoyo, 2016). Therefore, an abstract is one of the important factors in determining whether the reader will continue to read it or not (Kurniawan, Lubis, Suherdi, \&
Danuwijaya, 2019; Suryani \& Rismiyanto, 2019). The main function of abstract is to give the reader reflection of the article and decide whether to read the complete text or to evaluate that a piece of research us worth presenting or publishing (Bondi \& Sanz, 2014). Besides that, abstracts are required for graduation works such as undergraduate theses, postgraduate theses and dissertations, grant proposals, short communications, and for specific disciplinary purposes (Bondi \& Sanz, 2014). Because of that, the ability to write the research article abstracts effectively becomes pivotal when it is purposed to be published in international and reputable journals (Kurniawan, Lubis, Suherdi, \& Danuwijaya, 2019).

Because abstract is important, a number of studies on this topic have been conducted. The recent studies that focused on comparing abstract across discipline (Darabad, 2016; Suryani \& Rismiyanto, 2019) and abstract with different language (Amnuai, 2019; Kaya \& Yağiz, 2020). Based on the recent studies, comparative studies of abstracts is the current trend of studies on rhetorical structure (Kaya \& Yağiz, 2020). 
However, the result in one research cannot be applied in other research because of the different focus. Moreover, the study of comparing and contrasting abstracts of lecturers on different disciplines may not have been done. This topic is interesting to be observed. Among all the literature on postgraduate thesis writing, study on abstract seems to be defaulted (Ren \& Li, 2011). Writing a paper in English is challenging for people that use English as second language (i.e., L2 writers). This issue also happens in Indonesia. Publishing academic writing in English is the key factor of academic life (Kaya \& Yağiz, 2020). These L2 writers encountered troubles in writing academic texts accepted by international journals, editors, and reviewers (Flowerdew, 2008). In line with these reasons, study on abstracts of lecturers' final paper in different discipline will fill this gap.

Rhetorical moves in abstract is a move or pattern that is usually used to write the abstract in a wellstructure. Hyland (2000) in his book, distinguished a move-structure classification on abstracts. He divided the structure into five parts. There are introduction, purpose, method, product, and conclusion. By using this structure, the researcher will be easier to write an abstract and the reader would be easier to understand it. Hyland (2000) also mentioned that people with different disciplinary tend to write the abstract differently; for soft science people, such as in linguistics area or social area, they tend to situate their discourse with an Introduction and in the other side, hard science people such as in natural science area or technique area, they tend to write more on a description of the Method.

Therefore, the purpose of this study is to compare and contrast the abstracts of the lecturers from different disciplines and graduates from foreign and local universities to know the difference pattern or moves that they use. This study uses Hyland's (2000) five moves analysis as the main framework. This study will identify the move, steps used and the language features that appear in the abstracts of post-graduate theses and dissertations of the lecturers from soft science lecturer and hard science lecturer of Universitas Pendidikan Indonesia.

\section{METHODS}

\subsection{Research Design}

This research used a descriptive qualitative method. The five-move analysis by Hyland (2000) is the main framework to examine the rhetorical structure of abstracts in research articles. The purpose of this study is to identify the moves, steps, and language features in master theses and dissertations of lecturers from soft science (English) and hard science (Mathematics) from Universitas Pendidikan Indonesia. The results will be displayed in the forms of tables.

\subsection{Data Sources}

The study selected 4 abstracts from one lecturer of English Department and one lecturer of the Mathematics Department. The abstracts are taken from their master theses and dissertations. Not only do they have different disciplines, but the lecturers also have different educational backgrounds. The English lecturer graduated from local universities while the Mathematic lecturer graduated from foreign universities. This reason is also taken as the consideration so we can see the contrast. The analysis is done manually.

\subsection{Data Analysis}

In the Hyland's (2000) rhetorical move analysis, there are five moves: Move 1 - Introduction establishes context of the paper and motives for the research or discussion; Move 2 - Purpose indicates purpose and outline the intention behind the paper; Move 3 - Method provides information on design, procedures, assumption, approach, and data; Move 4 - Product states the main findings and the arguments; and Move 5 Conclusion interprets or extends results beyond scope of the paper, draws inferences, points to applications or wider implications.

Table 1. Hyland's (2000) Model of Rhetorical Moves in RA

\begin{tabular}{|c|c|c|}
\hline Move & Step & Label \\
\hline \multirow{4}{*}{ Introduction (I) } & 1 & Arguing for topic significance \\
\hline & 2 & Making topic generalizations \\
\hline & 3 & Defining the key term(s) \\
\hline & 4 & Identifying gap \\
\hline \multirow[t]{2}{*}{ Purpose (P) } & & Stating the research purpose \\
\hline & 1 & $\begin{array}{l}\text { Describing participants/ data } \\
\text { source }\end{array}$ \\
\hline \multirow[t]{2}{*}{ Method (M) } & 2 & Describing instrument(s) \\
\hline & 3 & $\begin{array}{l}\text { Describing procedure } \\
\text { context }\end{array}$ \\
\hline \multirow[t]{2}{*}{ Product (Pr) } & & Describing the main results \\
\hline & 1 & Deducing conclusion \\
\hline \multirow[t]{3}{*}{ Conclusion (C) } & 2 & $\begin{array}{l}\text { Evaluating the significance of } \\
\text { the research }\end{array}$ \\
\hline & 3 & Stating limitations \\
\hline & 4 & $\begin{array}{l}\text { Presenting recommendation or } \\
\text { implication }\end{array}$ \\
\hline
\end{tabular}

The procedure started by contacting the lecturer concerned to collect the abstracts. After that, the researcher examined the move, steps, and language features of the abstracts one by one. Next, the researcher tabulated the data into a table to find the result. Then, move and steps analysis is conducted by seeing the frequent occurrence and the percentage. After that, the tense, voice, and verb are examined. Last, the researcher made the conclusion and discussion from the findings. 


\section{FINDINGS AND DISCUSSION}

\subsection{General Findings}

Four abstracts with 39 sentences had been analysed in this study. For the abstract of the thesis from soft science (A1) there are 7 sentences while for the hard science (B1) there are 9 sentences. The abstract of dissertation from soft science (A2) has 8 sentences while the hard science (B2) there are 15 sentences. As we can see from the previous statements, the hard science abstracts had much more sentences if we compare it with the abstracts from science.

For the move, all of them used Move 1 until Move 5 sequentially. However, in the B2 abstract, Move 3 and Move 4 appeared repeatedly. As we can see, there is a cycle here between Move 3 and Move 4. The mathematics lecturer did some research for the dissertation. He used the previous finding to be the framework for the next research and find a new finding. In line with this, Hyland (2000) stated in his book that some longer abstracts, mainly in the sciences, also recycled moves throughout the abstract, often in order to highlight a series of results by presenting them as outcomes of different purposes or methods.

Table 2. General Findings

\begin{tabular}{|c|c|c|}
\hline \multirow[b]{2}{*}{ Abstract } & \multicolumn{2}{|c|}{ General Findings } \\
\hline & $\begin{array}{c}\text { Number of } \\
\text { sentences }\end{array}$ & Move/Pattern \\
\hline $\begin{array}{l}\text { Thesis of Soft } \\
\text { Science (A1) }\end{array}$ & 7 & $1-2-3-4-5$ \\
\hline $\begin{array}{l}\text { Thesis of Hard } \\
\text { Science (B1) }\end{array}$ & 9 & $1-2-3-4-5$ \\
\hline $\begin{array}{l}\text { Dissertation of } \\
\text { Soft Science (A2) }\end{array}$ & 8 & $1-2-3-4-5$ \\
\hline $\begin{array}{l}\text { Dissertation of } \\
\text { Hard Science (B2) }\end{array}$ & 15 & $1-2-3-4-3-4-3-4-5$ \\
\hline
\end{tabular}

\subsection{Move Occurrence in Each Abstract}

The analysis results showed that all abstracts use all moves, Move 1 - Introduction, Move 2 - Purpose, Move 3 - Method, Move 4 - Product, and Move 5 Conclusion. As we can see from the percentage in Table 3 , Move 3 and Move 4 have the biggest percentage. In the A1 abstract from soft science, Move 3 and Move 4 occurred the most and had an equal percentage, it is $29 \%$. The percentage for Move 1, Move 2, and Move 5 here were all the same which is $14 \%$. For the A2 abstract, Move 4 had $34 \%$ from all moves which was the biggest percentage. Move 1 and Move 3 have an equal percentage which is $22 \%$ from all of the abstract's moves. Move 2 and Move 5 had the same percentage yet also as the smallest percentage here which is $11 \%$ for each move.
In the B2 abstract from hard science, Move 3 had the biggest percentages which is $40 \%$. Next is Move 4 with $26 \%$ and Move 1 with 20\%. Move 2 and Move 5 had equal percentage which are $7 \%$. In contrast with all abstract, Move 1 had the biggest percentage in the B1 abstract which is $38 \%$. Then, Move 3 was $23 \%$ from all. Last, Move 2, Move 4, and Move 5 were the same which are $13 \%$ for each move.

The findings of move occurrence did not show a typical difference between abstracts in soft and hard science. However, the results here were contrasted with Hyland's (2000) statement in his book. He stated that soft science tends to write introduction section or Move 1 more while hard science people tend to write more description in method section or Move 3 (p. 70). Only B2 abstract or the dissertation that had the same pattern with Hyland's (2000) statement. In the other hand, this finding was in line with Suryani and Rismiyanto's finding (2019), which is Move 3 - Method and Move 4 - Findings are used frequently in soft science abstract. Besides, the finding that Move - 1 Introduction and Move 3 - Method were occurred often in hard science is in line with Omidian, Shahriari and SiyanovaChanturia's (2018) findings.

Table 3. Move Occurrence Percentage from Each Abstracts

\begin{tabular}{ccccc}
\hline \multirow{2}{*}{ Move } & \multicolumn{4}{c}{ Move Occurrence Percentage } \\
\cline { 2 - 5 } & $\mathrm{A} 1$ & $\mathrm{~B} 1$ & $\mathrm{~A} 2$ & $\mathrm{~B} 2$ \\
\hline Move 1 & $14 \%$ & $38 \%$ & $22 \%$ & $20 \%$ \\
Move 2 & $14 \%$ & $13 \%$ & $11 \%$ & $7 \%$ \\
Move 3 & $29 \%$ & $23 \%$ & $22 \%$ & $40 \%$ \\
Move 4 & $29 \%$ & $13 \%$ & $34 \%$ & $26 \%$ \\
Move 5 & $14 \%$ & $13 \%$ & $11 \%$ & $7 \%$ \\
\hline
\end{tabular}

\subsection{Step Analysis of Each Move}

After analysing the move, steps of each move were analysed. For Move 1, Move 3, and Move 5, there were some steps in each of the moves. While for Move $2-$ Stating research purpose and Move 4 - Describing the main result, there are just one step for each of them. First, in Move 1, most of the steps that appeared were Step 1 of Move 1 - Arguing for topic significance. Besides that, there was also Step 2 - Making topic generalization that stood alone and embedded with Step 3 - Defining key terms. For Move 3, Step 2 Describing instrument(s) appeared in all abstracts. In B2 abstract there was also Step 2 that embedded with Step 1 - Describing participants or data sources. We also found Step 3 - Describing procedure and context, in the hard science abstract. There was Step 3 which stood alone and embedded with Step 1 of Move 3. Step 1 of Move 3 - Describing participants or data resources, 
which stood independently and embedded with Step 2 are only found in the B2 abstract. In the abstracts of thesis from both disciplines used different steps for Move 5, Step 3 - Stating limitation for A1 and Step 4 Presenting recommendation or implication for B1. On the other hand, the abstracts of dissertation from both disciplines used Step 1 - Deducing Conclusion.

Thus, we found that Step 1 of Move 1 - Arguing topic significance used in all abstracts from different disciplines. However, there was a difference in Move 3 which is in hard science there was always Step 3 of Move 3 - Describing procedure and text. In Move 5 there was no significant contrast between two disciplines but the difference from the educational paper was highlighted because the dissertation abstract had the same steps which is Step 1 of Move 5-Deducing Conclusion.

Table 4. Step Occurrence from Each Move

\begin{tabular}{ccccc}
\hline \multirow{2}{*}{ Move } & \multicolumn{4}{c}{ Step Pattern } \\
\cline { 2 - 5 } & A1 & B1 & A2 & B2 \\
\hline \multirow{2}{*}{ M1 } & 1 & 2 & 1 & 2 \\
& & 2 & $2(3)$ & 1 \\
& & 1 & & 1 \\
\multirow{2}{*}{ M3 } & 2 & 2 & 2 & $3(1)$ \\
& 2 & $3(1)$ & $2(1)$ & 3 \\
& & & & $1(1)$ \\
\multirow{2}{*}{ M5 } & 3 & 4 & 1 & 2 \\
& & & & 1 \\
\hline
\end{tabular}

\subsection{Language Features in the Abstracts}

\subsubsection{Tense Occurrence}

In line with the previous explanation, Table 4 reveals the percentage of tense occurrence in the abstracts. In A1 abstract, there were $57 \%$ of present tense and $43 \%$ of past tense. The A2 abstract had $89 \%$ of present tense and $11 \%$ of past tense. The difference here was quite big. While in the hard science area, in B1 abstract present tense and past tense shared the equal number which are $50 \%$. Lastly, the percentage of past tense in the B2 abstract was $86 \%$ which is much bigger than the percentage of present tense, $14 \%$. Present tense is used because this tense annunciates that this research is alive (Nurhayati, 2017). Stated by James in Nurhayati (2017), on the other hand, past tense needs emphasizing or whenever a caution approach to applications and extensions seem warranted. In the purpose move, the choice of using tense, past or present, is basically a rhetorical or strategic choice rather than obligatory constraint (Salager-Meyer, 1992).
Table 5. Tense Occurrence in the Abstracts

\begin{tabular}{|c|c|c|c|c|}
\hline \multirow{3}{*}{$\begin{array}{l}\text { Abstr } \\
\text { act }\end{array}$} & \multicolumn{4}{|c|}{ Tense Occurrence } \\
\hline & \multicolumn{2}{|c|}{ Present } & \multicolumn{2}{|c|}{ Past } \\
\hline & $\begin{array}{c}\text { No. of } \\
\text { sentences }\end{array}$ & $\begin{array}{c}\text { Percentag } \\
\text { e }\end{array}$ & $\begin{array}{c}\text { No. of } \\
\text { sentences }\end{array}$ & Percentage \\
\hline A1 & 4 & $57 \%$ & 3 & $43 \%$ \\
\hline A2 & 8 & $89 \%$ & 1 & $11 \%$ \\
\hline B1 & 4 & $50 \%$ & 4 & $50 \%$ \\
\hline B2 & 2 & $14 \%$ & 13 & $86 \%$ \\
\hline
\end{tabular}

\subsubsection{Voice Occurrence}

The next language features that were analysed was the voice that appears in the abstracts. The results of the voice occurrence analysis are in percentage form. The A1 abstract in soft science, all of the sentences were in active voice or $100 \%$. In A2 abstract there were $89 \%$ of active voice and $11 \%$ of passive voice. The B1 abstract in hard science had the equal percentage of the voice occurrence which is $50 \%$ for both of them. The B2 abstract consisted of $73 \%$ of active voice and $27 \%$ of passive voice. As we can see from the data, the active voice was the voice that occurred the most in all abstracts. In line with this result, the international standard ISO 21421976 (E) has encouraged to use active voice as much as possible to make the text clearer and more concise (Liu \& Zheng, 2014)

Table 6. Voice Occurrence Percentage

\begin{tabular}{ccccc}
\hline \multirow{2}{*}{ Abstract } & \multicolumn{4}{c}{ Voice Occurrence } \\
& \multicolumn{2}{c}{ Active Voice } & \multicolumn{2}{c}{ Passive Voice } \\
\cline { 2 - 5 } & $\begin{array}{c}\text { No. of } \\
\text { sentences }\end{array}$ & $\%$ & $\begin{array}{c}\text { No. of } \\
\text { sentences }\end{array}$ & $\%$ \\
\hline A1 & 7 & $100 \%$ & 0 & $0 \%$ \\
B2 & 8 & $89 \%$ & 1 & $11 \%$ \\
B2 & 4 & $50 \%$ & 4 & $50 \%$ \\
\hline
\end{tabular}

\subsubsection{Verb Types}

The last analysis was analysing the verb types in the abstract. There are three categories here: action verb, linking verb, and helping verb. In A1 soft science abstract, action verb had the highest percentage which is $74 \%$. While the linking verb and the helping verb shared the same number, which is $13 \%$. In A2 abstract, the percentage of action verb and linking verb were equal in 44\%. Therefore, the helping verb had the smallest number which is $12 \%$. In B1 hard science abstract, helping verb was the highest number with $50 \%$. Then followed by action verb with $38 \%$ and linking verb with $12 \%$. The last is the B2 abstract had action verb that appeared the most in the abstract which is $53 \%$. Then followed by the helping verb which was $27 \%$ and 
the linking verb which was $20 \%$. As we can see, from all verb types, action verb is the most used verb types in abstracts. Maybe it can be more effective if the writer uses action verbs than the other types of verbs.

Table 7. Verb Types Occurrence Percentage

\begin{tabular}{ccccccc}
\hline \multirow{2}{*}{$\begin{array}{c}\text { Abstra } \\
\text { ct }\end{array}$} & \multicolumn{6}{c}{ Verb Types } \\
\cline { 2 - 6 } & $\begin{array}{c}\text { Action } \\
\text { No. of } \\
\text { senten } \\
\text { ces }\end{array}$ & \multicolumn{2}{c}{ Linking } & $\begin{array}{c}\text { No. of } \\
\text { senten } \\
\text { ces }\end{array}$ & $\%$ & $\begin{array}{c}\text { No. of } \\
\text { senten } \\
\text { ces }\end{array}$ \\
\hline A1 & 5 & $74 \%$ & 1 & $13 \%$ & 1 & $13 \%$ \\
A2 & 4 & $44 \%$ & 4 & $44 \%$ & 1 & $12 \%$ \\
B1 & 3 & $38 \%$ & 1 & $12 \%$ & 4 & $50 \%$ \\
B2 & 8 & $53 \%$ & 3 & $20 \%$ & 4 & $27 \%$ \\
\hline
\end{tabular}

\section{CONCLUSION}

In conclusion, there are some similarities and differences between the abstract in soft science and hard science final paper. The first similarity is both of the abstract from different disciplinary use all moves in their abstract. However, the dissertation abstract from hard science uses Move 3 and Move 4 repeatedly to highlight a series of results by presenting them as outcomes of different purposes or methods. There is a significant difference that appears here. Move 3 Method and Move 4 - Findings are used frequently in soft science abstract. Besides, Move - 1 Introduction and Move 3 - Method are occur often in hard science. In Steps analysis, there are no contrasting differences between two disciplines. Only the difference in Move 3 which is in hard science there is always Step 3 of Move 3 - Describing procedure and text. In Move 5 there is no significant contrast between two disciplines but the difference from educational paper is highlighted.

In language features analysis there are no contrasting differences, yet we found some similarities. The voice occurrence in both abstracts is active voice that has bigger percentage than the passive voice. The other similarity is the use of tense. Both of the abstracts dominantly use present tense. The last similarity is the use of verb types. The dominant verb type that appears in the abstract is the action verb. However, the abstract of thesis in the hard science field use more helping verb that the other type. Therefore, there is a difference between the move occurrences in both abstracts with different disciplines.

The results of this present study may be the references for the next study and enrich the existing literature of academic writing. For the further research, this study suggests boarder corpus and much more abstracts to be analysed from different disciplines, soft science and hard science. So, the significant result will be shown.

\section{ACKNOWLEDGMENTS}

This study was supported by a grant from the Research and Community Service Unit, Indonesia University of Education. The authors would like to express appreciation for all the support provided.

\section{REFERENCES}

Amnuai, W. (2019). Analyses of rhetorical moves and linguistic realizations in accounting research article abstracts published in international and Thai-based journals. SAGE Open, 9(1), 1-9. https://doi.org/10.1177/2158244018822384

Antoniou, M., \& Moriarty, J. (2008). What can academic writers learn from creative writers? Developing guidance and support for lecturers in higher education. Teaching in Higher Education, 13(2), 157-167. https://doi.org/10.1080/13562510801923229

Bondi, M., \& Sanz, R. (2014). Abstracts: Crosslinguistic, disciplinary, and intercultural perspectives. In Busch-Lauer, Abstracts in Academic Discourse - Variation and Change (pp. 43-63). Bern: Peter Lang

Darabad, A. (2016). Move analysis of research article abstracts: A cross-disciplinary study. International Journal of Linguistics, 8(2), 125-140. https://doi.org/10.5296/ijl.v8i2.9379

Flowerdew, J. (2008). Scholarly writers who use English as an additional language: What can Goffman's "Stigma" tell us? Journal of English for Academic Purposes, 7(2), 77-86. https://doi.org/10.1016/j.jeap.2008.03.002

Hyland, K. (2000). Disciplinary discourse: Social interactions in academic writing. Michigan: The University of Michigan Press.

Kaya, F., \& Yağiz, O. (2020). Move analysis of research article abstracts in the field of ELT: A comparative study. Dil ve Dilbilimi Çalışmaları Dergisi, 16(1), 390-404. https://doi.org/10.17263/jlls.712854

Kurniawan, E., Lubis, A., Suherdi, D., \& Danuwijaya, A. (2019). Rhetorical organization of applied linguistics abstracts: Does Scopus journal quartile matter? GEMA Online Journal of Language Studies, $\quad 19(4), \quad 184-202$ http://doi.org/10.17576/gema-2019-1904-10 
Liu, J., \& Zheng, R. (2014). A comparative study on voice distribution in English abstracts between Chinese and English power papers. Paper presented at the 2nd International Conference on Education, Management, and Social Science. https://doi.org/10.2991/icemss-14.2014.11

Muhartoyo. (2016). A study on completeness, finite verb tense, and voice of coconut research abstracts. Lingua Cultura, 10(1), 49-55. https://doi.org/10.21512/lc.v10i1.879

Nurhayati, N. (2017). Verb tense analysis of research article absract in Asian EFL journal. Progressive Journal, 12(2), 121-128. https://ejournal.nusamandiri.ac.id/index.php/progre ssive/article/view/572

Omidian, T., Shahriari, H., \& Siyanova-Chanturia, A. (2018). A cross-disciplinary investigation of multiword expressions in the moves of research article abstracts. Journal of English for Academic Purposes, 36, 1-14. https://doi.org/10.1016/j.jeap.2018.08.002

Ren, H., \& Li, Y. (2011). A comparison study on the rhetorical moves of abstracts in published research articles and master's foreign-language theses. English Language Teaching, 4(1), 162-166. https://pdfs.semanticscholar.org/d146/a4c03ca2cc7 d9b6bc4dd26dfe74bbf7d082d.pdf

Salager-Meyer, F. (1992). A text-type and move analysis study of verb tense and modality distribution in medical English abstracts. English for Specific Purposes, 11(2), 93-113. https://doi.org/10.1016/S0889-4906(05)80002-X

Suryani, F., \& Rismiyanto, R. (2019). Move analysis of the English bachelor thesis abstracts written by Indonesians. Prominent Journal, 2(2), 192-199. https://doi.org/10.24176/pro.v2i2.4229

Swales, J., \& Feak, C. (2009). Abstracts and the writing of abstracts. Michigan: University of Michigan. 